Estudios de la Paz y el Conflicto

Revista Latinoamericana

IUDPAS-UNAH

Número Especial 1, pp. 66-83

ISSN-e: 2707-8922 / ISSN: 2707-8914

DOI: $10.5377 /$ rlpc.v0i0.9504

Anual 2019

\title{
ANTROPOCENO, ¿COLAPSO DE LA ESPECIE?
}

\author{
ANTHROPOCENE, SPECIES COLLAPSE?
}

Luis Alberto Padilla

Instituto de Relaciones Internacionales e Investigaciones para la Paz

IRIPAZ-Guatemala

luis.alberto.padilla@iripaz.org

Cómo citar / citation

Padilla, L.A. (2019). “Antropoceno, ¿colapso de la especie?”, Estudios de la Paz y el

Conflicto, Revista Latinoamericana, Número Especial 1, 66-83. DOI:

10.5377/rlpc.v0i0.9504

\section{Resumen}

En este ensayo sostenemos que el Antropoceno no solo es una época geológica sino también un modelo cultural así como una propuesta de gobernanza holística y cosmopolita que debe guiarse por los objetivos de desarrollo sostenible (ODS) y la Agenda 2030 de Naciones Unidas, a fin de disminuir los riesgos de que el impacto ecológico del ser humano sobre el planeta desde la revolución industrial en el siglo XVIII conduzcan a la desaparición de la especie, riesgo que se ha visto incrementado desde la gran aceleración de mediados del siglo XX. Afirmamos también que para poder encaminar a todos los países por el sendero del desarrollo sostenible se requiere de una reforma profunda del sistema capitalista lo cual implica abandonar tanto el neoliberalismo como la idea que el crecimiento económico constituyen el criterio principal para evaluar los procesos de desarrollo, substituyendo ambas concepciones por la perspectiva de la gran transformación que implica hacer del desarrollo sostenible -incluyendo la satisfacción de las necesidades humanas y la conservación de los ecosistemas naturales- el paradigma necesario para salvar a la humanidad del conflicto y del colapso la especie.

Palabras claves: Antropoceno; holismo; cosmopolitismo; desarrollo sostenible; gran aceleración; gran transformación.

\footnotetext{
Abstract

In this essay we argue that the Anthropocene is not just a new geological epoch but a cultural model that could be used to promote a new type of world governance based on holism and cosmopolitanism guided by the sustainable development goals (SDGs) and the
} 
UN 2030 Agenda. Reduce the risks of species extinction that the human footprint on environment has produced on the planet since the industrial revolution at the XVIII century and the great acceleration of the mid XX century means essentially that a change of paradigm is needed forsaking the neoliberal and economic growth "models" and its substitution by a great transformation, a new thinking that could lead humanity trough the paths of a kind of sustainable development that protects environment and ecosystems at the same time that human needs are fully satisfied avoiding the species collapse.

Key words: Anthropocene, holism, cosmopolitanism, sustainable development, great acceleration, great transformation.

\section{INTRODUCCIÓN}

El Premio Nobel de Química Paul Crutzen (2000), científico holandés de renombre mundial, propuso durante una reunión de la Unión Internacional de Ciencias Geológicas celebrada en Cuernavaca (México) que se le diera el nombre de Antropoceno a la época geológica que estamos viviendo actualmente. El Holoceno -la época actual- se inició hace 12,000 años con el fin de la Edad del Hielo y el inicio del asentamiento sedentario de los seres humanos gracias a la agricultura, mientras que el Antropoceno se diferenciaría en el hecho de ser consecuencia del impacto ecológico que la revolución industrial del siglo XVIII tuvo sobre el planeta y sobre todo de la llamada "gran aceleración" de la post-guerra de mediados del siglo pasado por el salto exponencial del crecimiento demográfico, de la producción mundial, de los procesos de urbanización, de la agricultura (debido a la utilización de fertilizantes químicos), de la deforestación, de la construcción de represas, de la depredación de peces en los océanos, de la utilización de combustibles fósiles para generación de energía y para el transporte de todo tipo así como el incremento de los gases de efecto invernadero -el dióxido de carbono, el metano y otros- todo lo cual está provocando el calentamiento del clima terrestre.

El incremento de la temperatura del planeta está incidiendo en el retroceso de los glaciares y en el derretimiento del hielo en los casquetes polares con consecuencias en lo que se ha venido llamando como cambio climático que ha tenido efectos perniciosos en todo el globo terráqueo, debido a las cada vez más frecuentes inundaciones, sequías, grandes incendios forestales, tormentas tropicales, huracanes etc. que son de tal magnitud que la humanidad entera está corriendo el riesgo de una sexta gran extinción o colapso total de la especie.

El Antropoceno es entonces una nueva época geológica pero también -debido a la amenaza del cambio climático y a la aceleración que los humanos le hemos dado- puede considerarse como una nueva era o modelo cultural que requiere de otro tipo de gobernanza

\footnotetext{
${ }^{1}$ Se llama "Gran Aceleración" al salto vertiginoso que dan algunos indicadores tanto de tendencias socioeconómicas (población, PIB; inversión extranjera directa, urbanización, consumo de fertilizantes, construcción de represas, uso de agua, producción de papel, transportes y telecomunicaciones) como en los ecosistemas terrestres (dióxido de carbono, óxido de nitrógeno, metano, ozono, temperatura de la superficie terrestre, nitrógeno en las zonas costeras, deforestación de selva tropical, acuacultura marina, tierra dedicada agricultura y degradación de la biosfera) a partir de 1950 según comprobado por investigaciones del International Geosphere-Biosphere Program (IGBP) llevado a cabo entre los años 1999-2003 y cuyos resultados fueron publicados en 12 Gráficas icónicas por The Anthropocene Review (SAGE) Recuperado de http://www.commonhomeofhumanity.org-pdf

Estudios de la Paz y el Conflicto, Revista Latinoamericana, IUDPAS-UNAH, Número Especial 1, 2019, pp. 66-83. DOI: 10.5377/rlpc.v0i0.9504
} 
global porque entonces cabe la interrogante acerca de si es nuestra propia especie la que no solo constituye la principal amenaza para la vida de otras especies (dada la creciente extinción de especies y la reducción de la biodiversidad planetaria ) sino también para el mismo homo sapiens como lo piensa Lovelock (2007), el bien conocido autor de la teoría de Gaia quien afirma que o atendemos las advertencias de Gaia (la Tierra) o estamos arriesgando, de manera suicida, nuestra propia supervivencia.

Además de Lovelock, hay quienes también atribuyen a las relaciones del ser humano con el entorno medioambiental una de las principales causas del éxito o fracaso de las sociedades (Diamond, 2007) y con base en casos de estudio concretos -los mayas, los primitivos habitantes de la isla de Pascua o los primeros colonizadores noruegos de Groenlandia en el siglo IX - se ha podido comprobar que el colapso de tales sociedades ocurrió durante lo que -en términos de la historia del mundo occidental-, es considerado como "edad media".

Sin embargo, civilizaciones como la japonesa durante de la dinastía de los Tokugawa en el siglo XVI o bien los pueblos autóctonos de Nueva Guinea o de pequeñas islas del Pacífico sur si resolvieron adecuadamente sus problemas ecológicos, de manera que por ello dichas sociedades no solo han perdurado en el tiempo, sino que su relación con el medio ambiente es armónica y no destructiva.

\section{EL CAPITALISMO EN LA ERA DEL ANTROPOCENO.}

Otros investigadores (Angus: 2016) aunque aceptan que el Antropoceno es consecuencia del impacto ecológico de los humanos sobre el planeta atribuyen al capitalismo en tanto que modo de producción (Marx: 2013) y, particularmente, al llamado "capitalismo fósil"' de la actualidad una responsabilidad principal. No obstante, aunque el capitalismo sea el sistema económico predominante desde la época de la revolución industrial, en este ensayo sostenemos que la principal responsabilidad en el desastre ecológico que sufrimos actualmente radica en la perniciosa ideología económica del neoliberalismo en tanto que pensamiento hegemónico (Gramsci, 1949) de las elites dominantes, lo cual ha determinado la toma de decisiones de los gobiernos bajo la influencia del mal llamado Consenso de Washington $^{3}$ pues inclusive la larga tradición socialdemócrata de los países europeos se ha visto avasallada por este "modelo" neoliberal con los resultados negativos que eran de esperarse, incluso en regiones como Europa en donde habían prevalecido las políticas e ideas socialdemócratas. El auge del neo-nacionalismo xenofóbico de extrema derecha, con su retórica ideológica "soberanista" en contra de la integración y de la burocracia "no electa", "tecnocrática" y "opaca" de Bruselas se explica en parte por la decepción que ha producido en los trabajadores europeos la adopción de políticas de austeridad y de reducción del gasto

\footnotetext{
2 “Capitalismo fósil” es el nombre con el cuál Ian Angus denomina al tipo de capitalismo basado en la extracción de carbón, gas natural y petróleo para utilizarse tanto en la generación de energía eléctrica como en el uso de combustibles tales como la gasolina y el diésel, usados en aeronaves, barcos y toda clase de vehículos de transporte aéreo, marítimo y automotriz.

${ }^{3}$ Se ha llamado "consenso de Washington" a la doctrina económica neoliberal que considera que con políticas de liberalización comercial (disminución o eliminación de aranceles aduaneros), privatización de la propiedad pública y estabilización (que consiste en el también llamado ajuste estructural para mantener en equilibrio los presupuestos estatales evitando déficit excesivos, cosa que habitualmente los gobiernos llevan a cabo por medio de políticas de austeridad en el gasto y la inversión social) se mantiene un buen funcionamiento de la economía. Estudios de la Paz y el Conflicto, Revista Latinoamericana, IUDPAS-UNAH, Número Especial 1, 2019, pp. 66-83. DOI: 10.5377/rlpc.v0i0.9504
} 
social durante la gestión gubernativa de partidos socialdemócratas que dicen representarlos. Esta situación ha impulsado la creciente importancia electoral de personajes como Marine Le Pen, Nigel Farage, Geert Wilders, Umberto Bossi, Matteo Salvini, Bernd Lucke y otros, todos ellos líderes demagógicos nostálgicos de un pasado -el nacionalismo decimonónicoal que quisieran retornar.

Incluso Donald Trump es un neo-nacionalista de extrema derecha y su amañada llegada a la Casa Blanca (debido a las particularidades del sistema de elección indirecta -por medio de los delegados ante el Colegio Electoral- porque la ganadora del voto popular fue Hillary Clinton) puede considerarse como el resultado no deseado de las políticas en que incurrieron los demócratas norteamericanos cuando abandonaron el New Deal keynesiano y las políticas de intervencionismo estatal en la economía, instaurado desde tiempos de Roosevelt en los años treinta para combatir la recesión y la crisis capitalista de 1929. Recordemos que la administración Clinton le dio continuidad a las políticas neoliberales iniciadas por Ronald Reagan en la década de los ochenta, cuando entre otras cosas y gracias al North American Free Trade Agreement (en adelante, NAFTA) se desmantelaron industrias enteras para trasladarlas México a fin de aprovechar los salarios más bajos (Stiglitz, 2003 y 2015). El desencanto de las clases trabajadoras generó entonces el voto de estos obreros empobrecidos y sin posibilidad de obtener nuevos empleos para Trump y el partido Republicano. Y si esto ocurrió con los partidos socialdemócratas europeos y los liberales del partido demócrata americano obviamente con propuestas como las de la Comisión Bruntland ${ }^{4}$ (Bruntland: 1987) sobre desarrollo sostenible ocurrió otro tanto, siendo marginado de facto todo lo relacionado con el desarrollo sostenible en la toma de decisiones de las políticas económicas de los países bajo la influencia de Estados Unidos, y esto a pesar de que ya desde aquellos años las propuestas de Our Common Future (1987) eran la mejor alternativa para reformar el capitalismo salvaje implantado por el neoliberalismo.

En cuanto al capitalismo que se introdujo en la antigua Unión Soviética habría que decir que el colapso de la Unión Soviética fue consecuencia tanto de la ineficiencia económica como del pésimo manejo de la relación de la tecnología soviética con el medio ambiente (como lo demuestran los casos de Chernóbil y de la desaparición del Mar Aral). China no tuvo un colapso político, pero que su reconversión al capitalismo ha dado lugar a un crecimiento económico espectacular a costa de la depredación de sus recursos naturales y de una contaminación brutal que incluso podría estar vinculada al hecho significativo que epidemias o pandemias mundiales se han originado en ese país (como la actual enfermedad por coronavirus, en adelante COVID 19) pero que, sin embargo, no han tratado de poner en marcha políticas neoliberales (como si lo hicieron los rusos en la década de los noventa del siglo pasado sufriendo una crisis económica que solo terminó con la llegada de Putin al Kremlin) y que la economía de "capitalismo de Estado" se mantiene firmemente bajo el control del partido comunista. En consecuencia, se puede decir que en los países en donde predomina el capitalismo de Estado (bajo el control de los antiguos aparatchiks ${ }^{5}$ ) como

\footnotetext{
${ }^{4}$ La Comnisión Bruntland, como se ha llamado también a la Comisión Mundial sobre el Medio Ambiente y Desarrollo fue establecida por la Asamblea General de Naciones Unidas para elaborar una "Agenda Global para el Cambio" incluyendo estrategias de largo plazo para alcanzar el desarrollo sostenible el año 2,000 habiendo sido presidida por la exprimer ministra de Nortuega Gro Harlem Bruntland (de allí su nombre). La Comisión se integró con científicos y destacadas personalidades del mundo entero y en 1987 presentó un informe muy completo sobre el desarrollo sostenible denominado "Our Common Future".

${ }^{5}$ En idioma ruso el término aparatchiks se utilizaba para referirse a los cuadros del "aparato" del Partido Comunista que ostentaban posiciones de mando y dirección. Obviamente, fue relativamente fácil para este

Estudios de la Paz y el Conflicto, Revista Latinoamericana, IUDPAS-UNAH, Número Especial 1, 2019, pp. 66-83. DOI: 10.5377/rlpc.v0i0.9504
} 
Luis Alberto Padilla

Rusia, China, Vietnam o en las antiguas repúblicas soviéticas del Asia Central y del Cáucaso, es gracias a la intervención estatal en la economía que todos ellos pudieron salvarse de la crisis financiera provocada por Wall Street en el 2007-2008 y que -excepto por la ausencia de democracia política- este tipo de capitalismo es menos dañino para los trabajadores y las clases que todavía subsisten en situación de pobreza si los comparamos con lo que ocurre en los llamados países en vías de desarrollo en donde predomina el neoliberalismo (como sucede en buena parte de países latinoamericanos), porque es evidente que este "modelo económico" ha conducido a fenómenos de desigualdad y concentración de la riqueza de tal magnitud que han dado lugar a crisis sociales incluso en países que se consideraban el "modelo por excelencia", como sucedió en el Chile de Piñera en el 2019, y en otros cuyos gobiernos tuvieron un retroceso hacia el neoliberalismo (Ecuador con Moreno, Argentina con Macri, el Brasil de Bolsonaro) o que siempre han tenido gobiernos de ese signo ideológico (Guatemala, Honduras, El Salvador, Colombia). Un caso distinto es el de aquellos países en donde han sido las crisis políticas las determinantes de protestas masivas (Bolivia, Nicaragua, Venezuela) porque en ellos ha sido el autoritarismo y el déficit democrático el responsable de las protestas sociales. Por consiguiente, los únicos "casos aparte" de la región son los de Uruguay y de Costa Rica en donde gobiernos socialdemócratas han jugado un papel relevante para mantener la estabilidad social y política. Otras regiones del mundo como el Medio Oriente, el subcontinente indio o el sureste asiático merecerían análisis por separado, pero en términos generales tampoco disfrutan de condiciones excepcionales.

De manera que lo que realmente se plantea es la reforma del capitalismo tanto en el ámbito macroeconómico con el establecimiento de un sistema keynesiano de reciclaje de excedentes (Varoufakis, 2012) o impuestos al gran capital para disminuir la concentración de la riqueza y la desigualdad (Piketty, 2014) como en el ámbito microeconómico conforme a los casos novedosos descritos por Göpel (2016) o bien tomando ejemplo de casos históricos ejemplares como los estudiados por Diamond (2007). No obstante -y por fortuna- otra importante constatación que podemos hacer es que las calamidades del capitalismo neoliberal no significan que el desarrollo sostenible haya desaparecido de la escena. La mejor prueba de su persistente vitalidad es la Agenda 2030 y los 17 Objetivos de Desarrollo Sostenible (en adelante, ODS) aprobados por la Asamblea General de Naciones Unidas en Nueva York en septiembre del 2015 (2018) y que son de cumplimiento obligatorio para los 193 estados miembros de Naciones Unidas. De modo que la humanidad tiene todavía la oportunidad de apartarse de la amenaza que el capitalismo neoliberal supone para la vida en el planeta al haber adoptado los compromisos de la Agenda 2030 que fueron suscritos para dar cumplimiento a los ODS los cuales -evidentemente- van a requerir para su realización (sine qua non) de las reformas macroeconómicas del capitalismo "salvaje" propuestas por Varoufakis y Piketty para llegar a buen puerto así como - en la medida de lo posible - de la adaptación del tipo de experimentos microeconómicos descritos por Göpel, Richards, Diamond y otros investigadores ya mencionados.

segmento de la burocracia soviética adquirir la propiedad de los bienes que fueron privatizados en la década de "capitalismo salvaje" (neoliberal) durante los años que Boris Yeltzin (presidente de la Federación Rusa) gobernó contando con el consejo y asesoría de consultores del FMI y el Banco Mundial. Este tipo de capitalismo fue transformado en "capitalismo de Estado" (más o menos keynesiano, caracterizado por una fuerte intervención del Estado en la economía) con la llegada al poder del presidente Vladimir Putin.

Estudios de la Paz y el Conflicto, Revista Latinoamericana, IUDPAS-UNAH, Número Especial 1, 2019, pp. 66-83. DOI: 10.5377/rlpc.v0i0.9504 


\section{DESARROLLO NO ES SINÓNIMO DE CRECIMIENTO}

Sin embargo, también hay que decir que para hacer posible la reforma del capitalismo es indispensable una "Gran Transformación" del pensamiento económico (Polanyi,1983) y retornar a las necesidades humanas -y la conservación de los ecosistemas naturales- como los criterios centrales para evaluar la sostenibilidad de los procesos de desarrollo. Lo anterior significa también que hay que abandonar el crecimiento y el consumismo como patrones de orientación de la actividad económica -conforme a los dogmas neoliberales-porque si estos continúan prevaleciendo los pronósticos respecto a los resultados que se obtendrán en materia de ODS al final de la década se tornan sombríos. Una metodología holística (multidisciplinaria) y una filosofía cosmopolita debería contribuir de manera efectiva para disminuir los efectos perniciosos de la Gran Aceleración resultado del Antropoceno, época geológica en la que estamos instalados desde la segunda mitad del siglo pasado como ya se dijo. Por otra parte, dado que el Antropoceno no es solamente un fenómeno geológico sino es también un modelo cultural con una propuesta normativa -la "cosmopolítica" (Delanty y Mota, 2017)- el mismo tiene implicaciones epistemológicas para ir más allá del empirismo y del racionalismo, las dos visiones paradigmáticas de los tiempos modernos gracias a la inmersión del pensamiento contemporáneo en la física cuántica (Capra, 2007), en la teoría de los sistemas (Bertalanfy, 1989), en la ecología (Sachs, 2015) y en el postmodernismo filosófico (Tomassini, 1991).

Lo anterior nos permite comprender por qué el enfoque metodológico holístico es más apropiado para abordar la teoría de las relaciones internacionales - y no solo la cuestión elemental de que hasta ahora el énfasis se haya puesto en las relaciones entre Estados y no, como debería ser, entre naciones como indicado por el propio nombre de la disciplina- sino también porque si su objeto de estudio es el sistema-mundo (Wallerstein, 2006) que incluye al sistema internacional este último está compuesto por diversos subsistemas (político, militar, económico, cultural, religioso, social), que requieren del holismo multidisciplinario para llevar a cabo sus investigaciones.

En otras palabras, siendo las naciones conglomerados humanos que se identifican por una historia, espacio geográfico, lengua, religión, arte, costumbres, hábitos gastronómicos y culinarios etc.; es decir, por una cultura común, esto hace evidente que estudiar relaciones entre naciones implica un objeto de estudio que sobrepasa con creces las relaciones interestatales y que por esta misma razón se requiere también de un enfoque inter y transdisciplinario, que incluye tanto a las ciencias sociales como a las ciencias naturales, a la física -cuántica y astrofísica- paleontología, química, geología etc. Es por ello que una verdadera teoría de las relaciones internacionales tiene que dar cuenta de la enorme y compleja dimensión nacional de cada Estado que en el campo de las ciencias sociales también incluye a disciplinas particulares como la historia, la geografía, la economía, la sociología o a la antropología, de modo que es indispensable integrar todos estos campos de conocimiento. En consecuencia, tanto el holismo como el cosmopolitismo son fundamentales para comprender la problemática mundial contemporánea puesto que el sistema mundo es universal-cosmopolita- por su propia naturaleza.

\section{DESORDEN MUNDIAL Y SISTEMA DE WESTFALIA}

La gobernanza global ya no puede funcionar adecuadamente en el marco del viejo y anacrónico orden westfaliano de manera que es indispensable fortalecer a Naciones Unidas 
Luis Alberto Padilla

como la mejor opción para superar el actual desorden mundial resultado de las guerras, el terrorismo, la corrupción y el crimen transnacional organizado. Sin embargo, a pesar de los esfuerzos que los estados hacen en Naciones Unidas para asegurar un mínimo de estabilidad al sistema, es claro que en el futuro próximo o se reforma esta gran institución mundial diseñándose nuevas instancias y mecanismos para tratar los asuntos globales o la inseguridad mundial seguirá prevaleciendo y los intereses nacionales seguirán obstaculizando y entorpeciendo el buen funcionamiento de la entidad mundial. No hay más que echar un vistazo a la inoperancia del Consejo de Seguridad en casos graves de conflicto armado (como en Siria o en Yemen) o a la desfachatez con la que ciertos gobiernos (Guatemala y Honduras) han actuado recientemente para bloquear e impedir investigaciones sobre la corrupción de sus altas autoridades para percatarse de ello.

$\mathrm{Y}$ es en ese sentido que el cambio desde las estrechas y miopes visiones nacionales hacia una concepción cosmopolita puede convertirse en un instrumento mucho más efectivo para establecer un orden basado en la seguridad global y planetaria. El extremismo ideológico del nacionalismo decimonónico condujo tanto a las dos grandes guerras mundiales del siglo pasado como a conflagraciones menores -pero no por ello menos sangrientas y destructivasde las renovadas guerras balcánicas -en la antigua Yugoeslavia- durante la última década del siglo pasado. Y esas guerras demostraron hasta la saciedad la imposibilidad de enfrentar problemas y conflictos a partir de ópticas nacionales. O se coopera y se adoptan decisiones que favorezcan a todos los actores involucrados en un conflicto o la violencia destructiva y la anarquía se imponen. Ponerse de acuerdo adoptando políticas comunes que sean fruto del diálogo y de la negociación es un asunto de vida o muerte entre otras razones porque vivimos en planeta que en su realidad pura y dura carece de fronteras materiales (Wihtol de Wenden, 2009). Las fronteras nacionales no son más que líneas imaginarias inventadas por políticos y comandantes militares para reducir la incidencia de disputas territoriales, pero si bien estas demarcaciones abstractas fueron útiles en el pasado en la actualidad han dejado de serlo porque es evidente que la seguridad estatal no depende más de los límites territoriales de cada país en un mundo que se encuentra cada vez más globalizado, interdependiente e interconectado (Wihtol de Wenden, 2017).

El desmantelamiento de los controles fronterizos al interior de la Unión Europea es un buen ejemplo de cómo la integración regional no solo es el camino más apropiado tanto para una paz como para la seguridad internacional, haciendo disminuir la presencia de los nacionalismos extremos del pasado -como el fascismo italiano o el nacional-socialismo alemán- sacando a países enteros del subdesarrollo y promoviendo la democracia como ha sucedido en casos como los de Irlanda, España, Portugal o Grecia y está ocurriendo ahora mismo con los países que formaron parte del bloque comunista y de la antigua Yugoeslavia pues ya Eslovenia y Croacia forman parte de la Unión Europea y otros estados -como Serbia, Montenegro o Macedonia- esperan impacientes en la puerta.

Hoy en día las amenazas a la seguridad al interior de la Unión Europea provienen de factores externos (como el terrorismo o la necesidad de integrar apropiadamente a los flujos incesantes de migrantes que huyen de la pobreza y de la violencia en el Medio Oriente o en el África Subsahariana) pero las guerras internacionales entre los países miembros están descartadas de una vez por todas porque a nadie en su sano juicio se le ocurre siquiera pensar en la posibilidad de Francia declarando la guerra a Alemania o a Boris Johnson amenazando con bombardear Paris o Berlín porque Bruselas se hubiese negado a aceptar las condiciones de Londres para el Brexit. Y, a propósito, con todo lo lamentable que significa el hecho que 
los británicos hayan abandonado la UE convendría tener presente que semejante disparate fue consecuencia de los defectos del sistema uninominal electoral británico (como ocurre en EE.UU con la elección indirecta), casi tanto como del neo-nacionalismo de derecha y de la vieja tradición del pensamiento británico de considerarse como los offshore balancers del continente, radicalmente diferentes - por su insularidad geográfica- del resto de países europeos, fenómeno psicosocial que a pesar de haber dejado de tener importancia en éstos tiempos de la globalización, para los ingleses sigue teniendo su peso ideológico específico. Estos errores históricos son pues consecuencia del apoyo de un electorado nacionalista y conservador que frente a la carencia de estadistas - como si lo fue Churchill- ceden deslumbrados por la demagogia de un Nigel Farage o un Boris Johnson.

De manera que habrá que esperar que en el futuro sea el pensamiento cosmopolita de David Held (2012) Anthony Appiah (2007) o Gerard Delanty (2012) quienes se proyecten más allá de la Academia (o de los pasillos de la City londinense) para convencer al electorado conservador acerca de las virtudes de la integración. Esto facilitaría también que pensadores como Daniele Archibugi (1998), Ulrich Beck (2006), Jurgen Habermas (1988), Bertrand Badie (2011) Bruno Latour (2015), Edgar Morin (2011) a quienes se podría agregar el pensamiento de los antiguos estoicos romanos y del propio Immanuel Kant (2018) para contrarrestar con su influencia intelectual de gran estatura al anacrónico y mezquino nacionalismo xenofóbico de la extrema derecha europea, que carece de pensadores importantes. El mismo Mignolo (2011) ha dicho que ser ciudadano del mundo es perfectamente compatible con la posesión de múltiples identidades, lo cual supone que una persona puede ser a la vez un buen técnico en informática y un experto en la ecología de saberes (Santos, 2010a, 2010b) para su propio terruño. Y nada impide ser cosmopolita a un guatemalteco que además de centroamericano puede identificarse como maya, al igual que un buen cosmopolita europeo puede seguir siendo español vasco, catalán o gallego o también francés y bretón; alemán y bávaro; británico y galés, irlandés o escocés.

\section{LA DECADENCIA DE LAS SOBERANÍAS NACIONALES}

Otro tema de gran importancia se refiere a la globalización y a su relación con las soberanías nacionales. Y es que, aunque la globalización sea un resultado de acciones humanas, se trata de un fenómeno irreversible que ahora ya no se puede echar para atrás. Hoy en día, ningún gobierno está en condiciones de pedirle a sus ciudadanos que dejen de usar las computadoras de bolsillo que llamamos celulares porque nadie está dispuesto a prescindir de esos aparatitos a los cuales todos nos hemos vuelto adictos. Poco valen las alertas acerca de los riesgos de que en el futuro una inteligencia artificial sea capaz de manipularnos a través de ellos y controlar nuestras vidas (Harari, 2016) frente a un hecho tan simple como el uso generalizado -por ricos y pobres- de la telefonía móvil, lo cual demuestra fehacientemente que la globalización llegó para quedarse y que no estamos en condiciones de desmantelarla. Y esto se debe a que es el mercado mundial -no los mercados nacionales- el que constituye el destino de la mayor parte de la producción industrial del mundo y esto mismo explica que el comercio sea para el mercado mundial como el aceite de los automóviles o la sangre y la savia de todo ser viviente, de modo que también podemos extrapolar dicha imagen para referirnos a la inutilidad de oponerse a la libre movilidad de personas y mercancías fortificando las fronteras nacionales. El principio de territorialidad -eje fundamental del viejo orden de Westfalia- está en decadencia, aunque haya sido útil desde su establecimiento en el 
Luis Alberto Padilla

siglo XVI. Por eso mismo la única forma de superar las barreras fronterizas incapaces de detener la movilidad humana y los flujos comerciales sin causar mayores disturbios al orden establecido o desestabilizar al capitalismo mundial es por medio de los procesos de integración regional, dentro de los cuales, por supuesto, el más importante y paradigmático es el europeo, el cual -por eso mismo- debería servir de modelo para el resto del mundo, aunque cada región tenga - por supuesto- la posibilidad de imprimirle su propio sello y particularidades.

Por consiguiente, es claro que no es posible resolver el problema del desorden mundial como lo llama Haas (2017)-, restableciendo las seguridades del viejo orden de Westfalia algo que también sugiere Kissinger en su último libro sobre el Orden Mundial (2014) porque la interconectividad e interdependencia del mundo globalizado lo impiden y hacerlo a través de la fuerza con las políticas de cambio de régimen que los americanos han querido aplicar en el Medio Oriente, especialmente en países como Libia, Siria, Irak o Afganistán proyectando geoestratégicamente su maquinaria militar, no solo constituyen un evidente fracaso (las guerras y la crisis nunca terminan en esos desventurados países por culpa de Occidente, sólo en Afganistán la presencia militar norteamericana -y de la Organización del Tratado del Atlántico Norte, en adelante OTAN-, se acerca a los veinte años) sino que uno de los resultados más perniciosos de tales políticas ha sido precisamente el auge del terrorismo, porque tanto Al Qaeda como el ISIS (cuyas siglas en inglés - no por azar- significan "Estado Islámico en Irak y Siria"), solo han desaparecido en los sueños de Trump, no en la realidad. Y esto último a pesar de que habría que reconocer que rusos, iranís, sirios y kurdos si han logrado - utilizando medios brutales poco acordes con el derecho internacional humanitario, lo que los occidentales no han podido hacer, es decir, expulsar a los jihadistas de sus bastiones territoriales. En consecuencia, a pesar de los shows de distracción política de Trump (como el asesinato del general iraní Suleimani o el anunciado proceso de paz diseñado por la Casa Blanca para ambas partes pero del cual los palestinos se enteraron por Cable News Network, en adelante CNN), más le valdría al establishment político militar de Washington preocuparse porque al impredecible Trump no le ocurra desatar una nueva guerra de cambio de régimen contra Irán, ya que esto equivaldría a colocar al mundo entero al borde de una tercera guerra mundial, ya que indudablemente ni Moscú ni Beijing se quedarían con los brazos cruzados.

Lo antes señalado significa también que hay que cobrar conciencia que la confrontación o contradicción en que se encuentra la globalización con la geopolítica, la cual radica esencialmente en la oposición del principio de movilidad geoeconómica con el principio de territorialidad geopolítica, y percatarse que en semejante batalla es la segunda y sus defensores quienes llevan las de perder, no la primera y sus promotores. En consecuencia, para resolver tal oposición la soberanía estatal debería ser reinterpretada, porque ya no es la protección del territorio lo que está en juego, como ocurrió durante la antigüedad cuando los chinos quisieron protegerse construyendo los 8,000 kilómetros de la gran muralla, o como ocurría con las ciudades medievales, verdaderas fortalezas amuralladas y recordemos que aún a mediados del siglo pasado Francia se quiso proteger de la Alemania nazi con los 400 kilómetros de Línea Maginot que no sirvieron de nada frente a la fulminante blitzkrieg de Hitler que les jugó la vuelta a los franceses cuando atravesó con sus blindados el territorio belga para apoderarse de París. Convendría recordar estas lecciones de la historia al Trump de los sueños delirantes de impedir el ingreso de migrantes latinoamericanos construyendo un muro de 4,000 kilómetros en la frontera con México. Lo que realmente está en juego en 
el siglo XXI es la protección del planeta y la seguridad del globo terráqueo, no la de los pequeños, medianos o grandes estados-nacionales por más poderosos que se crean. Son entonces las llamadas "fronteras planetarias" (Sachs, 2015: 181-214) las que verdaderamente están en juego, no las fronteras nacionales.

Y reiteramos que la clásica noción de soberanía está en decadencia porque el punto crucial de las relaciones internacionales del siglo XXI no es el estrecho concepto de soberanía nacional sino la soberanía planetaria que se basa en los derechos de Gaia (Latour, 2015) -la Pachamama - ya inscritos en las constituciones nacionales de Bolivia y de Ecuador, puesto que el verdadero umbral para la seguridad contemporánea ha dejado de ser territorial para convertirse en seguridad humana y en seguridad del globo terráqueo, no de cada país. Lo anterior significa que es el agua dulce, los glaciares, los casquetes polares, los bosques y las selvas tropicales, los océanos, la biodiversidad y toda la vida natural que es tan valiosa e importante para la vida humana la que debe protegerse y conservar el buen funcionamiento de los ecosistemas terrestres para garantizar la seguridad de todos los habitantes del planeta tomando medidas para prevenir o combatir las amenazas que se ciernen sobre él -como el cambio climático, la contaminación atmosférica, las catástrofes naturales, el crimen organizado, las inesperadas epidemias de virus o una potencial conflagración nuclear (de las nueve potencias con ese tipo de armas que se niegan al desarme y han venido manteniendo el estancamiento de las negociaciones en el seno de la Conferencia de Desarme en Ginebra $^{6}$ )-, evitando así que tales amenazas provoquen el colapso de la civilización y de la especie humana sobre el planeta. Los gobiernos nacionales deben entonces adquirir consciencia que la cooperación es fundamental para enfrentar tales riesgos y amenazas aprendiendo a compartir las soberanías nacionales en función de la soberanía planetaria si no queremos que el planeta Tierra en tanto que super-organismo viviente (Lovelock, 2007) sea el que opte por librarse de nosotros.

\section{LA SEGURIDAD INTERNACIONAL DEPENDE DE LA SEGURIDAD HUMANA}

Sin embargo, tenemos que reconocer también que los procesos de larga duración histórica o grandes transformaciones sociales requieren de mucho tiempo para consolidarse, de manera que se debe aceptar que los problemas de seguridad en su significado tradicional para cada Estado -la seguridad de territorio, población y gobierno-, seguirán en la agenda de la política internacional "westfaliana" todavía por un buen número de años. Entonces, dado que estas preocupaciones están relacionadas con la geopolítica habría que insistir en que la salida de esta problemática reside en la utilización apropiada de las negociaciones multilaterales (G7, G20, Naciones Unidas, las Conferencias de las Partes en materia de cambio climático) de modo que la única forma de salir de la profunda crisis presente es perseverando en el fortalecimiento de Naciones Unidas pues el tipo de políticas públicas globales que se

\footnotetext{
${ }^{6}$ La Conferencia de desarme (CD) es un foro de negociación sobre desarme de carácter multilateral. Se fundó en 1979 como resultado de la primera Sesión Especial de Desarme de la Asamblea General de las Naciones Unidas que tuvo lugar en 1978 y se integra con 65 estados (incluyendo a las potencias nucleares) funciona por consenso, y ha negociado con éxito la Convención sobre Armas Biológicas, la Convención sobre Armas Químicas y el Tratado de prohibición total de ensayos nucleares. En el 2007 un tratado de reducción de materiales fisibles, la detención de la carrera armamentística en el espacio exterior y el desarme nuclear que no han progresado.
}

Estudios de la Paz y el Conflicto, Revista Latinoamericana, IUDPAS-UNAH, Número Especial 1, 2019, pp. 66-83. DOI: 10.5377/rlpc.v0i0.9504 
Luis Alberto Padilla

necesitan pueden y deben ser negociadas en el organismo mundial $-\mathrm{O}$ en los organismos regionales- aunque conviene recordar que esto debe hacerse substituyendo las herramientas propias de la tradicional diplomacia cooperativa con una nueva diplomacia de la solidaridad (Badie, 2011), buscando la concertación enfrentar los problemas de seguridad global que tienen que ver con el terrorismo, crimen organizado, ataques cibernéticos, cambio climático, guerras y conflictos armados de toda índole, refugiados y migrantes económicos, pandemias y epidemias (como el corona-virus), las hambrunas y las sequías, las tormentas tropicales y los huracanes, incendios forestales provocados por el calentamiento climático y el viento (como los catastróficos incendios que han devastado a Australia en el 2019), terremotos y erupciones volcánicas y un largo etcétera. Por otra parte, y en lo concerniente a la solución jurisdiccional de disputas territoriales, no hay que olvidar el importante papel que ha jugado la Corte Internacional de Justicia y el que debería jugar en el futuro la Corte Penal Internacional para preservar un mínimo de respeto al derecho internacional humanitario sancionando drásticamente a todos aquellos responsables de crímenes de guerra, sin necesidad de establecer tribunales especiales como se hizo en los casos de Ruanda y de la antigua Yugoeslavia.

Además hay que recordar también el otro tipo de consabidas amenazas para la seguridad global que se vinculan con la geoeconomía y con la seguridad humana porque lo mejor sería su renegociación multilateral bajo la óptica del desarrollo sostenible, es decir con base en la capacidad de los gobiernos nacionales para manejar los aspectos micro y macro de la dinámica social junto a los factores tecno-económicos debidamente articulados a los ecosistemas naturales, o, en otras palabras, hacer que el progreso lineal sea compatible con los patrones circulares propios de los ciclos naturales del planeta a fin de no traspasar las fronteras planetarias con las emisiones de Gases Efecto Invernadero (en adelante, GEI), el óxido de nitrógeno, la acidificación de los océanos, la integridad de la biósfera, el uso de suelos y del agua dulce, los flujos bioquímicos y de aerosoles así como disminuir el calentamiento del clima terrestre de fuente antropogénica para mitigar los efectos del cambio climático (o facilitar la adaptación de la población) de conformidad con los compromisos asumidos en la Conferencia de las Naciones Unidas sobre el Cambio Climático (en adelante, COP21) de Paris del 2015, como mínimo.

Otra amenaza para la seguridad internacional es consecuencia de la inseguridad humana estrechamente vinculada a una dinámica social que exige afrontar las amenazas que para el planeta entero supone no sólo el crecimiento demográfico sino la existencia de millones de personas en situación de pobreza, desnutrición crónica, enfermedad y opresión. Para ello hay hacer efectivos los compromisos de los gobiernos para resolver esta problemática contando con la guía de los ODS en relación a cuestiones tales como la obligación de mejorar los sistemas de educación y salud de cada país, garantizar la seguridad alimentaria, empoderar a la mujer, respetar los derechos de los pueblos indígenas, reducir la desigualdad social, mitigar vulnerabilidades y adaptarse al cambio climático, erradicar la corrupción, fortalecer el estado de derecho y la democracia, regularizar los flujos migratorios de todo tipo respetando el derecho a la movilidad, en fin, todo lo que debe convertirse en prioridad de las políticas públicas si queremos cumplir con los compromisos de la Agenda 2030.

Por cierto, el derecho a la movilidad humana debe ser también una prioridad de las políticas públicas globales porque el derecho a salir de su propio país (y retornar) es un derecho humano garantizado por la Declaración Universal de Derechos Humanos de 1948, de modo que a no ser que alguien haya cometido un delito, cualquier detención por motivos 
de irregularidad migratoria (la carencia de pasaporte o visa, el ingreso sin pasar por los controles migratorios de los puertos fronterizos o aeropuertos) debería ser considerado como una detención arbitraria lo que obligaría a todos los países a terminar con la criminalización de los trabajadores migrantes sancionando a los agentes estatales que incurriesen en estas detenciones arbitrarias así como en la deportación de personas detenidas por encontrarse en irregularidad migratoria ( o peor aún, en el abandono forzado de menores de edad como ocurre en Estados Unidos debido a las políticas xenofóbicas y antimigratorias de Trump.

Una solución para esta problemática podría inspirarse en el concepto de ciudadanía transnacional (Baübock, 2002) que no debería ser un privilegio exclusivo de los ciudadanos de la Unión Europea sino que convendría negociar normativas internacionales de regularización (tomando como base el pacto por una migración ordenada y regular aprobado en Marruecos en el 2018) a fin de regular las condiciones de movilidad para trabajadores de manera parecida a como de facto los ejecutivos (CEOs o cuadros técnicos) de las grandes empresas transnacionales ya gozan de tal privilegio o al tipo de visado que otorgan los países del Golfo y Alemania a los trabajadores egipcios y turcos, respectivamente. Así podría conseguirse una reducción en la aporofobia (Cortina, 2012), que consiste en las políticas de rechazo a los migrantes por su condición de pobreza.

Y por supuesto, si los países ricos desean disminuir los flujos migratorios de quienes no tienen oportunidades de trabajo en sus países de origen deberían invertir en ellos y pagar salarios decentes. Hay que terminar con la ideología neoliberal que ve en la "mano de obra barata" una ventaja comparativa. Con semejante criterio Henry Ford nunca hubiese podido pagar salarios decentes a sus trabajadores para que estos adquirieran los "Ford modelo T" producidos en serie por la industria automotriz, ni tampoco los países industrializados hubiesen podido establecer jamás su mercado interno gracias a lo cual se convirtieron en los países ricos y desarrollados que ahora son. Ni Inglaterra, Estados Unidos, Francia, Alemania, Italia, Japón, Corea, Taiwan o incluso la China de hoy en día serían lo que son sin sus respectivos mercados internos, la formación de una clase media y la apuesta que hicieron para industrializar sus economías. Ningún país del mundo se ha desarrollado a base de exportaciones de commodities o de la agricultura.

Además, el desarrollo supone también el trabajo decente -como le llama la Organización Internacional del Trabajo, en adelante OIT-, y por ende en pago de salarios apropiados para el ascenso social a la clase media que estará entonces en condiciones de participar en el mercado interno que es fundamental, aunque las oligarquías de los países pobres sigan insistiendo de manera equivocada en apostarle a los mercados externos. Hasta la Comisión Económica para América Latina y el Caribe (en adelante, CEPAL) se vio obligada a abandonar sus políticas de substitución de importaciones para recomendar un "regionalismo abierto" ante la influencia avasalladora del neoliberalismo y de la ya mencionada influencia de la doctrina neoliberal que fue dada en llamar como el Consenso de Washington" aunque -obviamente-, habría que constatar que quienes no se equivocaron son los trabajadores mismos, que optaron por emigrar a donde si se pagan salarios decentes. Hoy en día la solución de esta crisis profunda de inseguridad y subdesarrollo se encuentra en apostarle al desarrollo sostenible en cada país así como a los procesos de integración regional que sigan el modelo europeo es pues la única manera de salir del perpetuo subdesarrollo y también la mejor fórmula para garantizar tanto la seguridad humana (erradicar la pobreza) como la seguridad global, así como para disminuir los flujos migratorios y la inseguridad internacional que tanto preocupan a las clases dirigentes de los países ricos.

Estudios de la Paz y el Conflicto, Revista Latinoamericana, IUDPAS-UNAH, Número Especial 1, 2019, pp. 66-83. DOI: 10.5377/rlpc.v0i0.9504 
El sector privado y la comunidad empresarial pueden continuar preocupándose por el crecimiento económico y el rendimiento de sus inversiones pero acatando lo que señalen las normas de regulación del mercado en el marco de la legislación nacional (e internacional cuando sea el caso) y especialmente de aquellas destinadas a evitar la evasión fiscal, garantizar una mejor distribución de la riqueza en cada país, o hacer que la producción sea compatible con los ecosistemas regulando la descontaminación ambiental, el uso del agua, los precios de garantía para los pequeños y medianos campesinos, los intereses bancarios, la energía eléctrica, el gas natural, los biocombustibles incluyendo el tratamiento de los desechos sólidos para fabricar compost como fuente energética.

\section{PAZ POSITIVA Y DESARROLLO SOSTENIBLE}

Una paz positiva depende del desarrollo sostenible de la misma manera que la paz negativa depende del desarme y de la solución negociada de conflictos. El mercado debe ser regulado y el capitalismo salvaje (neoliberal) debe ser regulado, domesticado. Pero el crecimiento para ser sostenible requiere del respeto y conservación de los ecosistemas. De modo para lograr esto último se requiere que las energías renovables substituyan a los combustibles fósiles y que en los países pobres se debe combatir la deforestación y ampliar las áreas boscosas protegidas. En las áreas rurales el Estado debe proteger a la población local y aunque la energía proveniente de hidroeléctricas sea renovable y conveniente porque no contamina con emisiones GEI, su construcción debe hacerse de manera que no se afecten los derechos de las comunidades tanto al agua como a un precio justo por la energía eléctrica que debe ponerse a su disposición sin el pretexto que deben recurrir a los "distribuidores de energía" para tal propósito. Y tanto el uso de plásticos así como el manejo de desechos sólidos o aguas servidas deben ser regulados por el Estado y los combustibles fósiles (carbón y petróleo) deben ser substituidos por fuentes de energía renovable como la eólica, solar, geotérmica, de las mareas, hidráulica o incluso la nuclear - bajo la modalidad de la tercera generación de fisión o utilizando la fusión nuclear que será posible en un futuro próximo- y que esto se lleve a cabo en todos los países y no sólo en casos ejemplares como los de Costa Rica, Bután o Alemania. En suma, domesticar al capitalismo salvaje significa dar prioridad a los ODS, especialmente, en el terreno social y medio ambiental, conservando el buen funcionamiento de los ecosistemas, garantizando la regulación de los mercados y estableciendo sanciones para disminuir la corrupción, exigiendo los empresarios y a las grandes corporaciones trasnacionales un comportamiento ético y de conformidad con los principios de la responsabilidad social empresarial.

Además hay que impulsar políticas y legislación destinada procesos de integración regionales y las instituciones supranacionales (como en el caso de la Unión Europea) pueden trabajar en función del desarrollo sostenible si queremos que la globalización vaya más allá de la geopolítica y de los nacionalismos, trabajando para la gente y no para las elites, lo cual implica cobrar consciencia que la democratización del sistema internacional $-\mathrm{y}$ su legitimidad- requieren de un nuevo tipo de multilateralismo dotado de una visión mundocéntrica, basada en el cosmopolitismo como marco teórico que puede ayudar a prevenir y reducir el peligro de limpiezas étnicas al interior de los Estados, guerras o conflictos violentos especialmente en los lugares y regiones críticas como el Medio Oriente, el Kashmir, Afganistán, los mares del este y sur de la China, África, América Latina y todos aquellas 
regiones y países en donde el principio de territorialidad aún tiende a chocar con las tendencias hacia la integración.

\section{CONCLUSIÓN}

La cosmopolítica (y el cosmopolitismo como su fundamento filosófico) requiere de una "gran transformación" del pensamiento ${ }^{7}$ (Polanyi, 1983). Insistimos entonces en la necesidad de cobrar consciencia de que tanto la geopolítica como el principio de territorialidad son anacrónicos en el siglo XXI y que los gobiernos deberían ir substituyendo la vieja concepción de seguridad nacional por el concepto contemporáneo de seguridad global y planetaria. El cambio de pensamiento o "gran transformación" no será fácil porque así como para hacer efectivo el desarrollo sostenible se requiere abandonar la mentalidad neoliberal prevaleciente, en el ámbito de la seguridad global se requiere abandonar la idea de que las fronteras nacionales son primordiales substituyéndola por la concepción según la cual lo realmente importante es proteger las fronteras planetarias, es decir, los umbrales ecológicos que no deben traspasarse si se desea prevenir y disminuir los riesgos que implican las catástrofes ecológicas que cada vez serán más frecuentes debido al cambio climático. Y para mantener una paz transformadora (Ramos, 2015), hay que tener presente que la paz positiva (Galtung, 1981) es más importante que la paz negativa (ausencia de guerra), precisamente porque para darle durabilidad a la segunda hay que eliminar la violencia estructural proveniente de la pobreza y de la ausencia de desarrollo sostenible.

Por consiguiente, la paz entendida de manera positiva para sostenerse debe basarse en desarrollo social y humano pero nunca hay que olvidar el componente ecológico porque si no se elimina o reduce la amenaza del cambio climático las catástrofes naturales como los gigantescos incendios forestales en California, la Amazonia, Siberia y Australia del año 2019 o la sequía prolongada del África subsahariana así como los huracanes cada vez más frecuentes de la región del Caribe van a continuar provocando inseguridad y zozobra. Dicho de otra manera, siendo el calentamiento global resultado de la quema de combustibles fósiles que incrementan los gases de efecto invernadero en la atmósfera es evidente que somos los seres humanos - dada la huella ecológica de cada persona, pero fundamentalmente las clases dominantes que manejan la economía mundial-, a quienes debe adjudicarse la responsabilidad por un calentamiento terrestre que hoy en día constituye una amenaza peor que el terrorismo y otros flagelos como la guerra o el crimen organizado, de manera que no solo hay que criticar la realpolitik usual en las políticas exteriores de las grandes potencias, sino que requiere repensar la noción misma de seguridad avanzando hacia la idea de una paz ecológica (Brauch, 2019) sustentada en el respeto y preservación de los ecosistemas naturales.

\footnotetext{
${ }^{7}$ El término "gran transformación" proviene de la obra de Karl Polanyi refiriéndose a la transformación que sufrió el pensamiento occidental europeo durante el siglo XVIII cuando el liberalismo irrumpió con gran potencia en el proceso de modernización europeo transformando radicalmente costumbres, prácticas sociales y formas de pensamiento impulsado por las revoluciones políticas tanto en Inglaterra (Cromwell) como principalmente- en Francia gracias a la revolución francesa de 1789. La investigadora alemana Maja Göpel ha dicho en su libro sobre el gran cambio de mentalidad ("the great mindshift") que algo similar o análogo debe ocurrir en el pensamiento contemporáneo si el capitalismo neoliberal va a ser reformado por el paradigma del desarrollo sostenible.
}

Estudios de la Paz y el Conflicto, Revista Latinoamericana, IUDPAS-UNAH, Número Especial 1, 2019, pp. 66-83. DOI: 10.5377/rlpc.v0i0.9504 
En síntesis, en el mundo contemporáneo el desarrollo sostenible debe ser la respuesta a las múltiples amenazas a la seguridad así como a las crisis tanto políticas como económicas que azotan el planeta entero y ponen en peligro la sobrevivencia de muchas especies incluyendo a homo sapiens y tenemos que agregar que cuando escogimos el término "debe ser" en lugar de "puede ser" lo hicimos pensando en el sentido normativo del primero que se enlaza con la idea que la esfera del buen gobierno es uno de los cuatro componentes (junto a lo social, lo económico y lo ambiental) del desarrollo sostenible.

De modo que aunque sea fundamental reconocer que el deterioro antropogénico del planeta - principalmente provocado por alza de temperaturas derivada de la acción humana o, para ser más precisos, de la forma como funciona el capitalismo neoliberal que domina la economía mundial- se ha agravado a partir a la gran aceleración de la actividad económica de la postguerra en los años cincuenta del siglo pasado, habiendo dado origen a esta era del Antropoceno que más que una época geológica se ha convertido ya en tanto en paradigma científico como en "modelo cultural" que favorece la adopción una gobernanza cosmopolita y de una cosmopolítica (como la llaman Gerard Delanty y Aurea Mota) indispensable para abordar tanto el malestar de la civilización como la crisis climática teniendo una apropiada comprensión acerca de las políticas que deben promoverse en cada país pues no hay que olvidar que todavía vivimos en un mundo en el cual la nación-estado sigue siendo actor principal y también porque en ciertos casos descritos por los expertos acerca de casos concretos - como los mayas guatemaltecos emigrados a Estados Unidos- se puede constatar que si bien estos se han "desterritorializado" geográficamente también han recuperado su territorio en el país de acogida gracias a su cosmovisión de modo que el espacio social habitado por migrantes en ciudades como Los Angeles, Nueva York o Chicago es "reterritorializado" con la cultura, lo cual demuestra que el poder de los imaginarios sociales $\mathrm{y}$ del pensamiento es superior a las condiciones materiales de existencia y no se origina en ellas, como sostiene - para citar otro ejemplo- la teoría marxista.

La vida de los migrantes en los países de acogida (y esto es algo análogo a lo que ocurre con las corporaciones transnacionales o con algunas organizaciones de la sociedad civil global) se encuentran bajo la influencia de distintos marcos ideológicos, culturales, cosmovisiones o religiones en los diferentes niveles en que operan (locales, regionales, globales) debido a que ellos incorporan en su pensamiento y en sus ideas este tipo de espacios sociales multidimensionales, y tales creencias o formas de pensamiento se originan en las culturas locales, la familia, la religión y en la educación, no en la infraestructura económica o en la clase social como pensaba Marx.

En consecuencia, la situación del mundo contemporáneo -que incluye la trasnacionalización social y económica como una de sus principales características-, significa esencialmente que la cosmopolítica (y el cosmopolitismo) no es ninguna utopía que jamás se convertirá en realidad. Ludger Pries se refiere en su libro al llamado teorema de Thomas (Pries,2017) según el cual cuando una persona define una situación como real en su pensamiento esto adquiere realidad en sus consecuencias sociales, lo cual incluye no solo a la mentalidad y a las ideas sino también, por supuesto, al comportamiento y a las acciones sociales. Concluimos entonces reiterando que a pesar de que el orden internacional continúa siendo westfaliano políticamente tanto la globalización como la trasnacionalización ya lo han transformado económica, social y culturalmente. Podemos inferir así que lo que está en juego en el momento presente consiste en que las elites económicas y políticas mundiales deberían ajustar su pensamiento a la realidad so pena de desaparecer como consecuencia de un colapso 
colectivo de la civilización entera incluyendo al homo sapiens. Pero debemos concluir con una visión positiva y optimista viendo en la crisis la oportunidad y no la caída o el colapso. De modo que sólo será una cuestión de tiempo (aunque probablemente no tan rápido como lo quisiera el umbral de la Agenda 2030) el que se requiere para llegar a tener también una transformación del pensamiento y de las mentalidades colectivas que todavía permean la visión de las elites dominantes substituyéndolo por el paradigma holístico-cosmopolita que la era del Antropoceno demanda a fin de darle sostenibilidad al desarrollo. En otras palabras, si una mayoría de la población mundial comienza a definir la realidad en términos holísticos y cosmopolitas, asumiéndola como real en su pensamiento sus consecuencias sociales (que se vuelven prácticas sociales en el terreno económico) no deberían hacerse esperar demasiado tiempo para hacerse reales.

Evidentemente, abordar estos complejos problemas a escala mundial requeriría también de un esfuerzo colectivo para definir los procedimientos para que una ética de la madre tierra (Leonardo Boff, 2018) sea aplicada a las relaciones internacionales a fin de que el conocimiento proporcionado por las ciencias sociales, naturales y medio-ambientales se ponga en marcha por los tomadores de decisión, utilizando una metodología holística transdisciplinaria que debe ir aplicando el conocimiento de manera concreta a los diversos problemas que se suscitan cuando se trata de impulsar políticas de desarrollo sostenible según cada variable local. Así pues, de manera análoga a como se ha logrado hacer en los ejemplos exitosos en materia de conservación de superficie boscosa como los del Japón, la República Dominicana, las tierras altas de Nueva Guinea, Montana, los polders holandeses, los países escandinavos, Alemania o el Reino de Bután en los Himalayas, la civilización mundial debería aprender las lecciones acerca de porqué unas sociedades perduran y otras desaparecen. Por eso hemos enumerado en este ensayo algunas de esas cuestiones fundamentales cuyo conocimiento es imprescindible para que se hagan realidad las consecuencias sociales de ese nuevo pensamiento que habrá de llevar a cabo la "gran transición planetaria" (Raskin: 2202; 2016) que ya que se vislumbra en el horizonte.

\section{REFERENCIAS}

Angus, I. (2016). Facing the Anthropocene. Fossil capitalism and the crisis of the Earth System. New York: Monthly Review Press.

Appiah K.A. (2007): Cosmopolitismo. La ética en un mundo de extraños Buenos Aires, Madrid: Katz editors S.A

Archibugi D. \& Held D.(1998): Imagining Political Communities Studies in Cosmopolitan Democracy, London: Cambridge Polity Press

Badie, B. (2011). La diplomatie de connivence. Paris: Éditions La Découverte.

Baubock, R. (2002). How Migration Transforms Citizenship. International, Multinational and Transnational Perspectives. IWE-ICE Revue, 24.

Beck, Ulrich (2006): La Europa Cosmopolita. Sociedad y Política en la Segunda Modernidad, Madrid, Ediciones Paidos, Ibérica.

Boff, Leonardo (2018): Una Ética de la Madre Tierra. ¿ Cómo cuidar de la Casa Común? Cooperación Alemana [GIZ] Ciudad de Guatemala.

Brauch, H.G (2019). "Sustainable peace through sustainability transition as transformative science. A peace ecology perspective in the Anthropocene”, in Climate Change,

Estudios de la Paz y el Conflicto, Revista Latinoamericana, IUDPAS-UNAH, Número Especial 1, 2019, pp. 66-83. DOI: 10.5377/rlpc.v0i0.9504 
Disasters, Sustainability Transitions and Peace in the Anthropocene. Mosbach (Germany): Springer.

Capra, F. (2007). El Tao de la Física. Una exploración de los paralelismos entre la física moderna y el misticismo oriental. Buenos Aires: Editorial Sirio S.A.

Cortina, A. (2012). Ética Aplicada y Democracia Radical. Madrid: Editorial Tecnos.

Crutzen, P., Stoermer E. (2000). "The Anthropocene". Global Change Newsletter, 41. International Geosphere-Biosphere Program (IGBP): International Council of Sciences.

Delanty G. y Mota A. (2017): "Governing the Anthropocene: Agency, Governance, Knowledge", European Journal of Social Theory, 20 Anniversary special issue, SAGE Journals, 9-38.

Delanty, G. [ed.] (2012): Routledge Handbook of Cosmopolitan Studies, London \& New York: Taylor \& Francis Group Routledge

Diamond, J. (2007). Colapso. Porqué unas sociedades perduran y otras desaparecen. Ciudad de México: Random House Mondadori.

Göpel, M. (2016). The Great Mindshift. How a new economic Paradigm and Sustainability Transformations ho Hand in Hand. Mosbach (Germany): Wuppertal Institut \& Springer.

Gramsci A. (1982): Selection from the Prison Books, Lawrence and Wishart, London.

Habermas. Jurgen (1988): Teoría de la Acción Comunicativa. Crítica de la Razón

Funcionalista, Madrid: Taurus.

Haas, R. (2017). A World in Disarray. American Foreign Policy and the Crisis of the Old Order. New York: Penguin Press.

Harari, Y. (2016) Homo Deus. Breve historia del mañana. Ciudad de México: Penguin Random House.

Held, David (2012): Principles of Cosmopolitanism Order, in: Routledge Handbook of Cosmopolitan Studies, London \& New York.

Latour, B. (2015) Face a Gaia. Huit conférences sur le nouveau régime climatique. Paris: La Découverte.

Lovelock, J. (2007): The Revenge of Gaia: Why the Earth is Fighting Back and How We Can Still Save Humanity. New York: Penguin Press.

Kant, I. (2018): Hacia una paz perpetua. Un diseño filosófico. Madrid: CTK (ebooks) Alamanda.

Kissinger, H. (2014): World Order. New York: Penguin Press.

Marx, K. (2013). El Capital. Barcelona: Herder Editorial.

Mignolo, (2012) Decolonial colonialism and dialogues among civilizations, in: Routledge Handbook of Cosmopolitan Studies, London: Routledge.

Moran, Edgar (2011): La Vía para el Futuro de la Humanidad, Barcelona, Espasa Libros. Naciones Unidas (2018), La Agenda 2030 y los Objetivos de Desarrollo Sostenible: una oportunidad para América Latina y el Caribe (LC/G.2681-P/Rev.3), Santiago.

Piketty, T. (2014). Capital in the Twenty First Century. Cambridge Ma: Harvard University Press.

Polanyi, Karl (1983). La Grande Transformation. Aux origines politiques et économiques de notre Temps. Paris: nrf Gallimard.

Pries, L. (2017). La Transnacionalización del mundo social. Espacios sociales más allá de las Sociedades Nacionales. Ciudad de México: DAAD-El Colegio de México.

Ramos, E. (2015). Paz Transformadora y Participativa. Teoría y Método de la Paz y el Conflicto desde la Perspectiva Sociopráxica. Tegucigalpa (Honduras): Instituto

Estudios de la Paz y el Conflicto, Revista Latinoamericana, IUDPAS-UNAH, Número Especial 1, 2019, pp. 66-83. DOI: 10.5377/rlpc.v0i0.9504 
Universitario en Democracia, Paz y Seguridad-Universidad Nacional Autónoma de Honduras (IUDPAS-UNAH).

Raskin, P.(2002). The Great Transition. The Promise and Lure of the Times Ahead, Stockholm Environment Institute \& Global Scenario Group, Boston MA.

Raskin, P. (2016). Journey to Earthland. The Great Transition to Planetary Civilization. Boston MA: Tellus Institute.

Sachs J. (2015). The Age of Sustainable Development. New York: Columbia University Press.

Santos, B. de S. (2010a). Refundación del Estado en América Latina. Perspectivas desde una Epistemología del Sur. Bogotá: Universidad de los Andes \& Siglo XXI editores.

Santos, B.de S. (2010b). Una Epistemologia del Sur. México: CLACSO coediciones Siglo $\mathrm{XX}$.

Stiglitz, J. (2003). The Roaring Nineties. New York: Norton.

Stiglitz, J. (2015). Unequal Societies and What Can We do about Them. New York: Norton.

Tomassini, L. (1991). La Politica Internacional en un Mundo Post Moderno. Buenos Aires Grupo Editor Latinoamericano \& RIAL.

Varoufakis, Y. (2012). El Minotauro Global. EE.UU, Europa y el Futuro de la Economía Mundial. Ciudad de México: Ediciones Culturales Paidós.

Von Bertalanfy, L. (1989). Teoría General de los Sistemas, Ciudad de México: Fondo de Cultura Económica (FCE).

Wallerstein, I. (2006): Análisis de los Sistemas Mundo, Una introducción, Ciudad de México, Siglo XXI editores S.A

Wihtol de Wenden, C. (2009). La Globalisation Humaine. Paris: Presses Universitaires de France (PUF).

Wihtol de Wenden C. (2017). Faut-il ouvrir les frontières? Paris: Sciences Po.

World Commission on Environment and Development [Bruntland Commission](1987). Our Common Future. New York: Oxford University Press.

\section{REFERENCIA DEL AUTOR}

Luis Alberto Padilla, Doctorado en Ciencias Sociales por la Universidad de París II (Panteón-Sorbona). Profesor de Teoría de las Relaciones Internacionales en la Escuela de Ciencia Política de la Universidad de San Carlos, de Derecho Internacional Público en la Facultad de Derecho de la misma Universidad y de Geopolítica Mundial en la Universidad Rafael Landívar. Ex secretario General del Centro Latinoamericano de Investigación para la Paz (CLAIP). Fundador del Instituto de Relaciones Internacionales e Investigaciones para la Paz (IRIPAZ) en Guatemala (miembro de IPRA y de CLAIP) Diplomático de carrera ha sido Viceministro de Relaciones Exteriores y embajador en Naciones Unidas (Ginebra y Viena) así como en Rusia, Países Bajos, Austria y Chile. Email: luis.alberto.padilla@iripaz.org

Recibido: 13-02-2020

Aceptado: 17-02-2020

(c) (i) Licencia Creative Commons Reconocimiento 4.0 (CC BY 4.0).

Estudios de la Paz y el Conflicto, Revista Latinoamericana, IUDPAS-UNAH, Número Especial 1, 2019, pp. 66-83. DOI: 10.5377/rlpc.v0i0.9504 